\title{
$\mathrm{LaNi}_{1-x} \mathrm{Ti}_{x} \mathrm{O}_{3}(x \leq 0.5)$ 세라믹스의 전기전도 특성
}

\author{
정우환 ${ }^{\dagger}$ \\ 호원대학교 전자공학과
}

\section{Electrical Transport Properties of $\mathrm{LaNi}_{1-x} \mathrm{Ti}_{x} \mathrm{O}_{3}(x \leq 0.5)$ Ceramics}

\author{
Woo-Hwan Jung ${ }^{\dagger}$ \\ Department of Electronics, Howon University, 727, Impi, Wolha-ri, Kunsan, Jeonbuk 573-930, Korea
}

(2008년 12월 23일 접수 : 2009년 2월 20일 최종수정 : 2009년 2월 23일 채택)

\begin{abstract}
Thermoelectric power and resistivity are measured for the perovskite $\mathrm{LaNi}_{1-x} \mathrm{Ti}_{x} \mathrm{O}_{3}(x \leq 0.5)$ in the temperature range $77 \mathrm{~K}-300 \mathrm{~K}$. The measured thermoelectric power of $\mathrm{LaNi}_{1-x} \mathrm{Ti}_{x} \mathrm{O}_{3}(x \leq 0.5)$ increases linearly with temperature and is represented by $A+B T$. The $x=0.1$ sample showed metallic behavior, the $x=0.3$ showed metal and insulating transition around $150 \mathrm{~K}$, and $x=0.5$ showed insulating behavior the over the whole temperature range. The electrical resistivity of $x=0.1$ shows linear temperature dependence over the whole temperature range and $T^{2}$ dependence. On the other hand, the electrical resistivity of $x=0.3$ shows a linear relation between $\ln \rho$ and $T^{-1 / 4}$ (variable range hopping mechanism) in the range of $77 \mathrm{~K}$ to $150 \mathrm{~K}$. For $x=0.5$, the temperature dependence of resistivity is characteristic of insulating materials; the resistivity data was fitted to an exponential law, such as $\ln (\rho / T)$ and $T^{-1}$, which is usually attributed to a small polaron hopping mechanism. These experimental results are interpreted in terms of the spin polaron $(x=0.1)$ and variable range hopping $(x=0.3)$ or small polaron hopping $(x=0.5)$ of an almost localized $\mathrm{Ni}^{3+} 3 d$ polaron.
\end{abstract}

Key words metallic conductivity, metal-insulator transition, polaron, variable range hopping, thermoelectric power.

\section{1. 서 론}

페로브스카이트 계 $3 d$ 천이 금속 산화물의 전기전도 특성에 관한 연구는 최근 십 수년간 많은 관심을 받아 왔다. ${ }^{1-4)} 3 d$ 천이금속 산화물이 많은 연구자 들에게 관심 을 받는 이유는 강자성, 강유전성, 초전도, 금속-절연체 전이 그리고 거대 자기 저항효과 등 학문적이며 기술적 인 면에서 매우 흥미로운 현상을 나타내기 때문이다. 일 반적으로 $A \mathrm{AO}_{3}$ 로 표현되는 페로브스카이트 계 $3 d$ 천이 금속산화물은 $A$-site 이온이 $\mathrm{Sr}, \mathrm{Ca}$ 그리고 $\mathrm{Ba}$ 과 같은 2+ 원소일 경우 $4+$ 전자가를 가진다. 반면 $A$-site 이온이 $\mathrm{La}$, $\mathrm{Pr}$ 과 같은 $3+$ 이온일 경우 $3+$ 전자가를 가진다. 일반적 으로 $B$ - site의 전자가가 $3+$ 일 경우 대부분의 $A B \mathrm{O}_{3}$ 페로 브스카이트 산화물은 절연체적 거동을 나타낸다고 알려 져 있다. ${ }^{5-7)}$

그러나 $\mathrm{LaNiO}_{3}$ 는 $\mathrm{Ni}$ 의 전자가가 $3+$ 임에도 불구하고 금속적 거동을 나타내며 실온에서 조차 매우 낮은 저항 을 나타낸다. ${ }^{8)}$ 또한 $\mathrm{LaNiO}_{3}$ 는 박막형 전자소자의 전극

Corresponding author

E-Mail: phdjung@howon.ac.kr (W. H. Jung)
재료 (특히 epitaxial 다층 페로브스카이트 박막)로서 매 우 가능성이 높은 재료로 평가 받고 있다. ${ }^{9} \mathrm{LaNiO}_{3}$ 는 $1.7 \mathrm{~K}$ 온도 까지 금속적 거동을 나타내는 것으로 알려져 있지만 동일 한 전자거동을 나타내는 $R \mathrm{NiO}_{3}(R=\mathrm{Pr}, \mathrm{Nd}$, $\mathrm{Sm})$ 은 각각 다른 온도에서 금속-절연체 전이를 나타낸 다. ${ }^{10)}$ 일반적으로 천이금속산화물의 전기적 성질은 Zaanen - Sawatsky-Allen (ZSA)의 전자상태도에 의하여 설명되 어지며 절연체적 거동을 나타내는 $R \mathrm{NiO}_{3}$ 은 전하 전달 절 연체로 구분되어진다. ${ }^{11)} 1990$ 년대에 행하여진 광학실험 및 상태밀도계산결과에 따르면 $R \mathrm{NiO}_{3}$ 의 금속-절연체전이는 전도 밴드 폭의 변화에 따라서 발생하게 된다고 보고 하 고 있다. ${ }^{12)}$ 따라서 이 재료들의 금속 및 절연체적 거동 은 전도 밴드 폭을 구성하는 $\mathrm{O} 2 p$ 와 $\mathrm{Ni} 3 d$ 의 결합 각 즉 $\mathrm{Ni}-\mathrm{O}-\mathrm{Ni}$ 결합 각에 따라서 달라진다고 할 수 있다. $\mathrm{LaNiO}_{3}$ 는 $\mathrm{Ni}-\mathrm{O}-\mathrm{Ni}$ 의 결합 각이 $180^{\circ}$ 에 접근하기 때문 에 금속적 거동을 나타내나 $R \mathrm{NiO}_{3}$ 의 경우 $R$ 원소의 이 온 반경이 작아짐에 따라 $\mathrm{Ni}-\mathrm{O}-\mathrm{Ni}$ 의 결합 각이 $180^{\circ}$ 보다 작아지기 때문에 전도 밴드 폭이 감소에 따라 절 연체적 거동을 나타내는 것으로 보고 되고 있다. ${ }^{13)}$

기존 $A B \mathrm{O}_{3}$ 페로브스카이트 산화물에 대한 연구는 $A$-사 이트에 $2+$ 원소의 치환에 의한 $B^{3+}$ 와 $B^{4+}$ 이온생성에 따른 
전기전도 변화가 주 대상이었다. 그러나 $\mathrm{LaNiO}_{3}$ 의 $\mathrm{Ni}^{3+}$ 은 $3 d^{7}$ 저스핀배열의 $t_{2 g}^{6} e_{g}^{1}$ 의 전자구조를 가지고 있기 때문 에 $\mathrm{LaNiO}_{3}$ 의 전도현상은 $e_{\mathrm{g}}^{1}$ 궤도에 의하여 지배 받고 있 으므로 $\mathrm{Ni}$ 계는 $R \mathrm{Ni}_{1-\mathrm{x}} M_{\mathrm{x}} \mathrm{O}_{3}(\mathrm{M}: \mathrm{Co}, \mathrm{Fe}, \mathrm{Cu}$ etc) 또는 $\mathrm{La}_{1-\mathrm{x}} R_{\mathrm{X}} \mathrm{NiO}_{3}$ 와 같은 $\mathrm{Ni}^{2+}$ 와 $\mathrm{Ni}^{3+}$ 의 이온의 전자가 변환에 따른 전기전도의 변화가 주요연구 대상중에 하나 였다. ${ }^{14-18)}$ 일반적으로 $\mathrm{LaNiO}_{3}$ 는 고온에서 열처리되기 때문에 산소 결함( $\delta$ )이 발생하게 되어 $\mathrm{K}_{2} \mathrm{NiF}_{4}$ 구조를 가지는 $\mathrm{La}_{2} \mathrm{NiO}_{4}$ 구조로 변화하고자 하는 경향이 있으며 산소결함 $(\delta)$ 때 문에 발생하는 $\mathrm{Ni}^{2+}$ 는 $\mathrm{Ni}-\mathrm{O}-\mathrm{Ni}$ 결합 각을 변화시키기 때문에 $\mathrm{LaNiO}_{3}$ 의 전기전도에 매우 중대한 영향을 미치 게 된다.

따라서 $R \mathrm{NiO}_{3}$ 의 연구에서는 $\mathrm{Ni}^{2+}$ 의 제어가 매우 중 요한 사항이다. 본 연구에서는 기존의 $R \mathrm{NiO}_{3}$ 의 $\mathrm{Ni}$ - site 에 $\mathrm{Ti}^{4+}$ 를 치환함에 따라 전하 중성화에 따른 $\mathrm{Ni}^{2+}$ 를 제 어 함으로써 발생하는 $\mathrm{LaNi}_{\mathrm{x}} \mathrm{Ti}_{\mathrm{x}} \mathrm{O}_{3}$ 의 전기전도 특성의 변 화를 보고 하고자 한다. 실제 $A B \mathrm{O}_{3}$ 페로브스카이트 산화 물의 $B$ - site에 $\mathrm{Ti}^{4+}$ 를 치환함에 따라 발생하는 전기전도 의 변화에 대한연구는 $\mathrm{Mn}, \mathrm{Co}$ 그리고 $\mathrm{Fe}$ 등에 대하여서 는 많이 행하여 지고 있으나, ${ }^{19-21)} \mathrm{Ni}, \mathrm{Cu}$ 등과 같이 금 속적 거동을 나타내는 재료에 대하여서는 많지 않은 편 이다.

\section{2. 실험 방법}

본 실험에서는 $\mathrm{LaNi}_{\mathrm{x}} \mathrm{Ti}_{\mathrm{x}} \mathrm{O}_{3}(x=0.1,0.3,0.5)$ 을 시험 대상으로 선택하였다. $\mathrm{LaNi}_{\mathrm{x}} \mathrm{Ti}_{\mathrm{x}} \mathrm{O}_{3}$ 는 $\mathrm{La}\left(\mathrm{NO}_{3}\right)_{3} \cdot 6 \mathrm{H}_{2} \mathrm{O}$, $\mathrm{Ni}\left(\mathrm{NO}_{3}\right)_{2} \cdot 6 \mathrm{H}_{2} \mathrm{O}$ 그리고 $\mathrm{C}_{10} \mathrm{H}_{14} \mathrm{O}_{5} \mathrm{Ti}$ 를 이용하여 액상 혼 합법으로 제작하였다. Citric산에 화학양론 적으로 평량 된 시료를 녹인 후, 혼합체를 공기 중에서 $873 \mathrm{~K}$ 의 온도에 서 열처리 후 $1073 \mathrm{~K}$ 온도에서 재열처리 하였다. 이때 얻 어진 분말을 이용하여 성형 후 $1227 \mathrm{~K}$ 의 온도 그리고 산 소분위기 중에서 24시간 소결하였다. 시편은 단일상이 얻 어질 때 까지 수 차례 분쇄 및 성형을 반복하여 열처 리 하였다. 대다수의 $3 d$ 천이 금속 산화물은 고온에서 열 처리 되는 관계로 산소 결핍 (또는 과잉)현상이 발생하게 되어 시편의 화학조성이 변화 하게 된다. 따라서 본 실험 에서 사용한 시편의 화학적 조성은 $\mathrm{La}\left(\mathrm{Ni}_{1-\mathrm{y}}^{3+} \mathrm{Ni}_{\mathrm{y}}^{2+}\right)_{1-\mathrm{x}} \mathrm{Ti}_{\mathrm{x}} \mathrm{O}_{3 \pm \delta}$ 의 형태로 나타내는 것이 타당하다. 변화된 산소의 양( $\delta$ ) 을 조사하기 위하여 idometric titration을 실시하였다. 고 온에서 열처리 하였음에도 불구 하고 시료의 $\delta$ 는 $x=0.1$, 0.3 의 경우는 -0.01 정도의 산소 결핍 그러나 0.5 의 경우 는 +0.01 정도의 산소과잉으로 나타났다. 따라서 본 연구 에 사용된 시편의 화학조성은 $\mathrm{La}\left(\mathrm{Ni}_{0.866}^{3+} \mathrm{Ni}_{0.134}^{2+}\right)_{0.9} \mathrm{Ti}_{0.1} \mathrm{O}_{2.99}$, $\mathrm{La}\left(\mathrm{Ni}_{0.543}^{3+} \mathrm{Ni}_{0.457}^{2+}\right)_{0.7} \mathrm{Ti}_{0.3} \mathrm{O}_{2.99}$ 그리고 $\mathrm{La}\left(\mathrm{Ni}_{0.04}^{3+} \mathrm{Ni}_{0.96}^{2+}\right)_{0.5} \mathrm{Ti}_{0.5} \mathrm{O}_{3.01}$ 로 나타낼 수 있다. $\mathrm{Ti}$ 의 치환양이 0.5 이상인 경우 $\mathrm{La}_{2} \mathrm{Ni}_{2} \mathrm{O}_{5}$ 와 같은 2 차상이 발생하였다. 시편의 색깔은 전부 검정
색 이었으며 분말 $\mathrm{x}$-선 회절 결과 $x=0.1$ 의 경우 능방 정 그리고 $x=0.3$ 및 0.5 의 경우 사방정 구조를 가지고 있음을 알 수 있었다. 결정격자 정수는 최소 자승 법을 이용하여 계산 하였다. 고 순도의 $\mathrm{Si}(5 \mathrm{~N})$ 분말을 내부기 준재료로 사용하여 회절 각 $2 \theta$ 아 $80^{\circ}-120^{\circ}$ 사이의 $\mathrm{x}$-선 회 절결과를 이용하였다. 실온에서의 격자상수는 $x=0.1$ 의 경우 $a_{\mathrm{hex}}=5.478, c_{\mathrm{hex}}=13.214 \AA, x=0.3$ 의 경우 $a=5.463, b=$ $5.530, c=7.825 \AA$ 로 나타났다. 그리고 $x=0.5$ 의 경우 $a=5.519, b=5.554, c=7.855 \AA$ 로 나타났다.

열기전력측정 및 전기저항을 측정하기 위하여 시편은 $3 \times 3 \times 18 \mathrm{~mm}^{3}$ 의 직사각형 bar를 제작 후 $77 \mathrm{~K}$ 에서 300 $\mathrm{K}$ 의 온도 영역에서 2 개의 $13 \% \mathrm{Ph} / \mathrm{Pt}-\mathrm{Pt}$ 열전대를 이용 하여 일반적인 방법을 이용하였다.

\section{3. 결과 및 고찰}

Fig. 1 에는 $x=0.1,0.3$ 그리고 0.5 의 비저항의 온도의 존성을 나타내었다. $x=0.1$ 의 경우 비저항의 온도의존성 은 금속적 거동을 나타내고 있는 반면, $x=0.3$ 의 경우 $150 \mathrm{~K}$ 부근의 온도영역에서 금속-절연체 전이가 관측되었
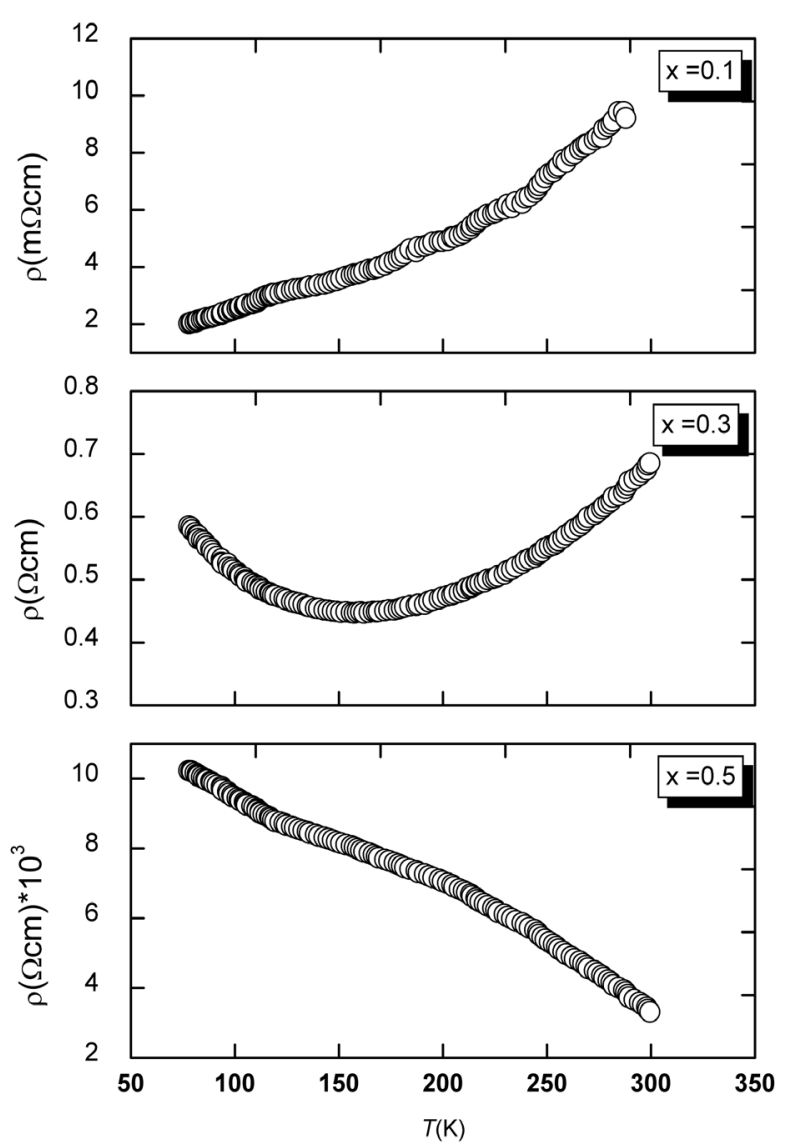

Fig. 1. The temperature dependences of the resistivity of $\mathrm{LaNi}_{\mathrm{x}} \mathrm{Ti}_{\mathrm{x}} \mathrm{O}_{3}$. 
다. 0.5 의 경우 전체 측정범위에서 절연체적 거동을 나 타내었으며 실온에서의 비저항은 0.1 및 0.3 에 비하여 최 소 $10^{3}$ 에서 $10^{5}$ 정도 크게 나타났다.

Fig. 2 에는 $\mathrm{LaNi}_{\mathrm{X}} \mathrm{Ti}_{\mathrm{x}} \mathrm{O}_{3}$ 의 열기전력의 온도의존성을 나 타내었다. $x=0.1,0.3$ 의 경우 음 $(-)$ 의 열기전력을 나타내 었다. 그림에는 나타내지 않았지만 $x=0.5$ 의 경우 양 $(+)$ 의 열기전력을 나타내었다. $x=0.1,0.3$ 의 경우 열기전력 의 온도의존성은 온도와 더불어 직선적으로 증가 하였지 만 $x=0.5$ 의 경우 높은 저항으로 인하여 저온에서는 열 기전력의 측정이 용이하지 않았으며 실온 부근에서 약 $+10 \mu \mathrm{V}$ 정도로 양의 열기전력을 나타내었다.

우선적으로 위의 두 실험 결과로 알 수 있는 것은 $\mathrm{Ti}^{4+}$ 의 치환양이 증가 할수록 비저항이 증가 하고 있음을 알 수 있었다. 이것은 $\mathrm{Ti}^{4+}$ 의 증가에 따라서 전도 carrier의 양이 감소하고 있음을 의미한다. 즉 $\mathrm{Ni}^{3+}$ 에 치환된 $\mathrm{Ti}^{4+}$ 에 의하여 $\mathrm{Ni}^{2+}$ 의 양이 증가한 것으로 사료된다. 이전에 설명하였듯이 $\mathrm{LaNiO}_{3}$ 의 전기전도는 $d$ 궤도의 $\mathrm{Ni}^{2+}$ 와 $\mathrm{Ni}^{3+}$ 의 에너지간의 차이에 의하며 결정되어 진다고 알려져 있 다. ${ }^{5-8)}$ 바꾸어 설명하면 $\mathrm{Ni}^{2+} \mathrm{Ni}^{3+}$ 의 상대량에 의하여 결 정되며 $\mathrm{Ni}^{2+}$ 의 증가는 $\mathrm{Ni}^{3+}$ 편력 전도 carrier (본 연구에서 는 음의 전자라고 생각함)의 양을 감소 시킨다. $\mathrm{Ti}^{4+}$ 미 치환 $\mathrm{LaNiO}_{3}$ 가 음의 열기전력을 ${ }^{10)}$ 나타내는 것도 이와 같은 맥락이다. 열기전력의 측정에서 잘 알 수 있듯이 $\mathrm{Ti}^{4+}$ 의 양이 증가 함에 따라 열기전력의 절대량은 감소 하고 있으며 $x=0.5$ 에서 양으로 변화 하였다. 이것은 $x=$ 0.5 의 경우 전도 carrier는 hole으로 변화 하였음을 알 수 있으며 $\mathrm{Ni}^{2+}$ 가 전도를 지배하고 있기 때문이라 사료된다.

또한 $\mathrm{Ti}^{4+}$ 의 치환에 따라 $\mathrm{LaNi}_{\mathrm{x}} \mathrm{Ti}_{\mathrm{x}} \mathrm{O}_{3}$ 는 페로브스카이트 형 구조를 나타내지만 치환량에 따라서 결정구조가 변화

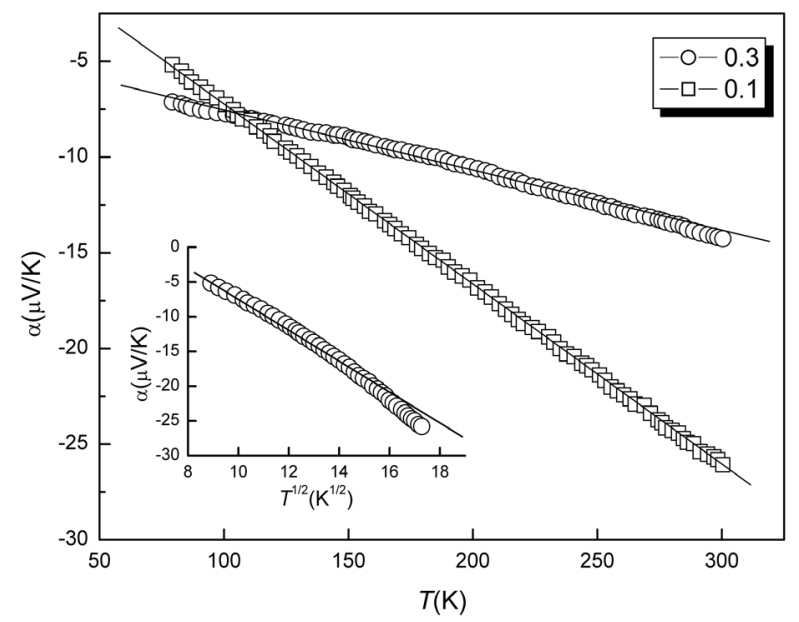

Fig. 2. The temperature dependences of the thermoelectric power of $\mathrm{LaNi}_{\mathrm{x}} \mathrm{Ti}_{\mathrm{x}} \mathrm{O}_{3}$. [Inset]: The plot of thermoelectric power versus $T^{1 / 2}$ for $x=0.3$. The solid line represents the fitting curve with variable range hopping.
함을 알 수 있다. 결정격자와 결정 군은 포함하고 있는 음 이온의 전하량과 크기에 따라서 변화하게 되며 일반적으 로 Goldscmidt 요소 즉 $t[t=d(A-O) / \sqrt{2 d(B-O)}]$ 의하여 결정된다. ${ }^{16)}$ 여기서 $d(A-O)$ 와 $d(B-O)$ 는 음이온과 산소간의 결합거리를 나타낸다. $t$ 는 일반적으로 능방정 구 조가 사방정 구조 보다 크게 된다. $t$ 가 1 에 가깝다는 것 은 $\mathrm{Ni}-\mathrm{O}-\mathrm{Ni}$ 결합 각이 $180^{\circ}$ 에 접근한다는 것을 의미한 다. $\mathrm{Ni}-\mathrm{O}-\mathrm{Ni}$ 결합 각 이 작아지면 $\mathrm{NiO}_{6}$ 팔면체의 왜곡 이 증가하여 hopping 전달자가 감소하게 되며 이는 저 항률의 증가를 가져오게 된다. ${ }^{17)} \mathrm{Ti}^{4+}$ 의 첨가에 따라서 $\mathrm{Ni}^{2+}$ 의 증가는 $\mathrm{Ni}$ 의 배위를 팔면체에서 사면체로 변화시 키며, 사면체배위에서는 전자간의 전달이 매우 어렵게 된 다. 또한 사면체배위는 $\mathrm{Ni}-\mathrm{O}-\mathrm{Ni}$ 결합 각을 감소시켜 전 도 band 폭을 감소 시키기 때문에 비저항을 증가 시킨 다. ${ }^{15-17)}$ 본 실험에서 나타난 것처럼 $x=0.1$ 의 경우 능방 정, $x=0.3,0.5$ 의 경우 사방정으로 나타났다. 따라서 이 전에 설명한 것처럼 능방정이 사방정에 비하여 $t$ 가 크기 때문에 $x=0.1$ 의 조성이 0.3 과 0.5 에 비하여 비저항이 매 우 작으며, 0.3 에 비하여 0.5 의 경우 비저항이 크게 증 가 한 것은 격자정수 계산 결과에서 알 수 있듯이 $\mathrm{Ti}^{4+}$ 의 증가에 따라서 격자정수의 크기가 증가 했으며 이는 이온반경이 큰 $\mathrm{Ni}^{2+}(0.69 \AA)$ 의 증가와 더불어 이온반경이 작 은 $\mathrm{Ni}^{3+}(0.56 \AA)$ 가 감소했기 때문이다. 또한 이온 반경이 큰 $\mathrm{Ni}^{2+}$ 의 증가는 $t$ 의 감소를 유발 저항이 증가 한 것 으로 사료된다.

Fig. 3 에는 $x=0.1$ 의 비저항 의 온도의존성을 나타내 었다. 그림에 나타난 것처럼 $x=0.1$ 의 온도의존성은 측 정범위 내에서 금속적 거동을 나타내고 있었다. 일반적 으로 저항의 변화가 금속적 거동을 나타낼 경우 비저항의 온도의존성은 $\rho=\rho_{0}+R T^{\alpha}$ 의 형태로 표시할 수 있다. ${ }^{22)} \mathrm{Ti}$

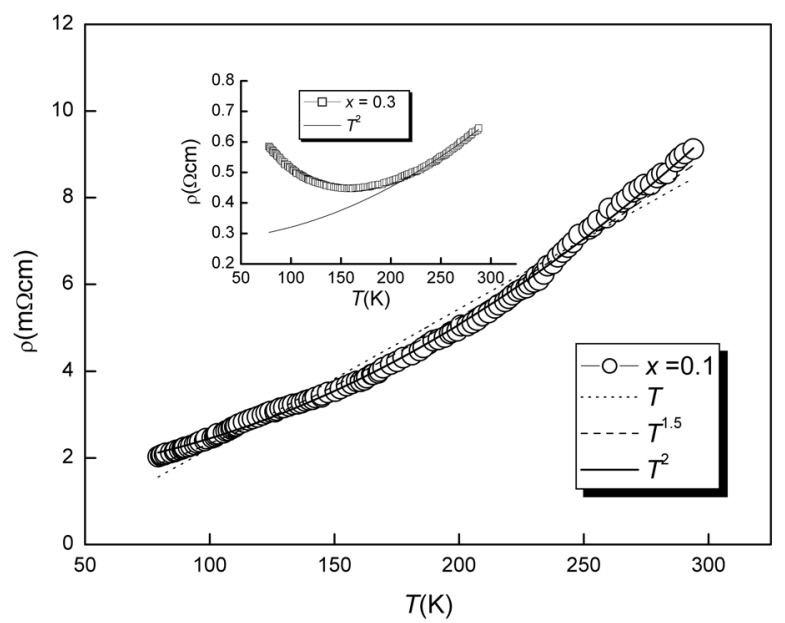

Fig. 3. The resistivity of the $\mathrm{LaNi}_{0.9} \mathrm{Ti}_{0.1} \mathrm{O}_{3}$ sample with the fits to the $\rho=\rho_{0}+R T^{\alpha}$ law. [Inset]: The resistivity of $x=0.3$ sample and fits to the $\rho=\rho_{0}+R T^{2}$. 
가 치환되지 않은 $\mathrm{LaNiO}_{3}$ 의 경우 비저항의 온도의존성 은 $\alpha$ 가 1 인 $\rho=\rho_{0}+R T$ 의 형태로 표시 할 수 있다고 보 고 되고 있다. ${ }^{14)} \mathrm{Fig}$. 3 에는 $\alpha$ 가 1 인경우의 비저항의 온 도의존성을 $\alpha$ 가 1.5 및 2 인 경우와 함께 나타내었다. 그

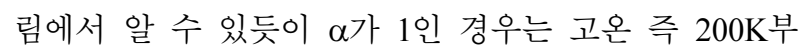
근에서 만 fitting되고 있음을 알 수 있다. 또한 $\alpha$ 가 1.5 인 경우 저온 부근에서는 잘 fitting되고 있으나 고온 부 근에서는 잘 fitting되고 있지 않음을 알 수 있다. 그러 나 $\alpha$ 가 2 인 경우가 전체 온도 영역에서 잘 fitting 되고 있음을 알 수 있다. 이것은 $x=0.1$ 조성이 강한 상관금속 또는 Fermi-liquid임을 증명해주는 좋은 증거라고 할 수 있다. ${ }^{22)} \rho=\rho_{0}+R T^{2}$ fitting 결과 $\rho_{0}=1.57 \mathrm{~m} \Omega \mathrm{cm}$ 그리고 $R$ 은 $8.7 \times 10^{-8} \Omega \mathrm{cmK}^{-2}$ 이었다. $x=0.1$ 의 조성의 비저항의 온도의존성이 전반적으로 $T^{2}$ 에 의존하는 것은 강한 electron-electron 상호 작용에 의한 spin polaron이 전도 를 지배하는 것으로 사료된다.

Fig. 4 에는 $x=0.3$ 의 비저항의 온도의존성을 나타내었 다. Fig. 1(b)에 나타낸 것처럼, $x=0.3$ 조성의 경우 $150 \mathrm{~K}$ 부근에서 금속-절연체 전이를 나타내고 있었다. $x=0.3$ 의 고온부(금속 영역)의 저항률의 온도의존성은 $x=0.1$ 과 같이 $T^{2}$ 에 의존 하는 것으로 나타났다. (Fig. 3 삽입그 림 참조) 저온부(절연체영역)에서의 비저항의 온도의존성 은 다음과 같이 설명 할 수 있다. ZSA등에 의하면 $\mathrm{LaNiO}_{3}$ 는 전하 전달형 절연체 (charge transfer insulator) 로 구분할 수 있고, ${ }^{11)}$ 전하 전달형 절연체에서 금속-절 연체전이가 발생할 경우, 절연체 영역에서의 전기전도는 일반적으로 열적으로 활성화된 전자의 hopping 또는 small polaron에 의한 전기전도가 발생하는 것으로 알려 져 있다. ${ }^{23-25)}$ 그러나 본 실험에서와 같이 화학적 첨가에 따른 $\mathrm{Ni} / \mathrm{Ti}$ 의 무질서가 발생하고, system 내에 충분히 분 포되었을 경우 variable range hopping이 발생하게 되며

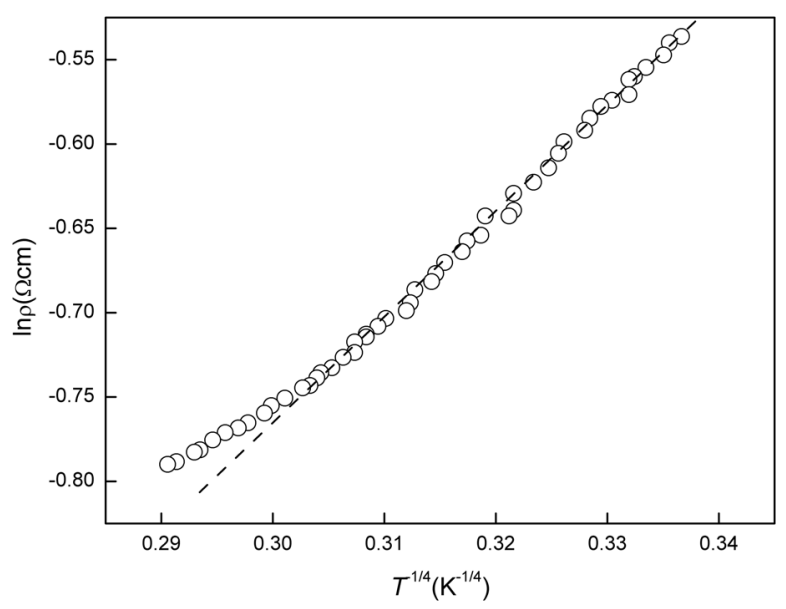

Fig. 4. The plot of $\ln$ versus $T^{1 / 4}$ for $x=0.3$ sample in the low temperature region.
금속영역에서는 상관금속 또는 Fermi-liquid 역할이 기대 된다고 보고 하고 있다. ${ }^{15)} \mathrm{Fig} .3$ 의 삽입그림에서 나타 내었듯이 $x=0.3$ 의 경우 고온에서의 비저항의 온도의존 성은 $T^{2}$ 에 의존하고 있는 것으로 보아 저온영역에서의 전 기전도는 variable range hopping에 의하여 지배 받고 있 는 것으로 사료된다. 만약에 전도가 variable range hopping에의 하여 지배 받을 경우 비저항의 온도의존성 은 다음과 같이 나타낼 수 있다. ${ }^{26,27)}$

$$
\rho=\rho_{0} \exp \left(\frac{T_{0}}{T}\right)^{1 / 4}
$$

또한 상수 $\rho_{0}$ 및 $T_{0}$ 는 다음과 같이 나타낼 수 있다.

$$
\begin{aligned}
& \rho_{0}=1 / e^{2} a^{2} v_{p h} N\left(E_{F}\right) \\
& T_{0}=18 \xi^{3} / k_{B} N\left(E_{F}\right)
\end{aligned}
$$

여기서 $a$ 는 속박거리 (일반적으로 속박거리는 격자정 수를 넘을 수 없다), $e$ 는 전하량, $v_{\mathrm{ph}}$ 는 광학적 phonon 주파수 $\left(10^{13} \mathrm{~s}^{-1}\right), N\left(E_{\mathrm{F}}\right)$ 는 Fermi면에서의 상태밀도, $k_{\mathrm{B}}$ 는 Boltzmann 상수 그리고 $\xi$ 는 속박상태와 관련이 있는 파 동함수 감쇄의 역수 이다. Fig. 4에 나타난 것처럼 비저 항의 온도의존성은 저온부근에서 $T^{-1 / 4}$ 에 의존하고 있으 며, 이 직선으로부터 얻어진 $\rho_{0}$ 및 $T_{0}$ 는 $0.072 \Omega \mathrm{cm}$ 와 $1.52 \times 10^{3} \mathrm{~K}$ 였다. 이 실험결과로부터 얻어진 $\xi$ 와 $N\left(E_{\mathrm{F}}\right)$ 는 $2.79 \times 10^{6} \mathrm{~cm}^{-1}$ 그리고 $2.79 \times 10^{21} \mathrm{eV}^{-1} \mathrm{~cm}^{-3}$ 이었다. 이와 같은 결과는 기존에 보고 되어 있는 $\mathrm{Ni}$ 계 산화물에서 얻어진 실험결과에 매우 유사한 결과이다. ${ }^{15)}$ 저온에서 이루어지 는 variable range hopping을 명확하게 하고자, 저온영역 에서의 전도 carrier의 hopping 거리 및 hopping energy 를 계산 할 필요가 있다고 사료된다. carrier의 hopping 거리 $R=\left[3 / 2 \pi \xi N\left(E_{\mathrm{F}}\right) N\left(E_{\mathrm{F}}\right) k_{\mathrm{B}} T\right]^{1 / 4}$ 그리고 hopping energy $W=3 / 4 \pi R^{3} N\left(E_{\mathrm{F}}\right)$ 로 표시할 수 있다. ${ }^{26,27)} 90 \mathrm{~K}$ 에서의 $R$ 과 $W$ 는 $2.92 \times 10^{-7} \mathrm{~cm}$ 그리고 $3.18 \times 10^{-3} \mathrm{eV}$ 였다. 온도가 감소 함에 따라 $R$ 이 증가 함으로 $W$ 는 감소하게 될 것 이다. 저온영역에서 carrier간의 결합에너지는 결정계의 무질서 에너지 보다 작기 때문에 저온에서는 carrier의 hopping 에너지는 결정계의 무질서에너지와 동일하다고 할 수 있 다. 따라서 $\mathrm{LaNi}_{0.7} \mathrm{Ti}_{0.3} \mathrm{O}_{3}$ 세라믹스에서 저온영역(절연체영 역)에서 $3.18 \times 10^{-3} \mathrm{eV}$ 의 미약한 에너지가 존재한다는 것 은 절연체 Energy gap 속에 좁은 불순물 band 속에 존 재하고 있다는 것을 의미한다. 저온영역의 경우, 좁은 불 순물band속에서 불순물전도 (impurity conduction)가 발 생하며 온도의 증가에 따라 variable range hopping기구 에 의하여 속박된 carrier간의 전도가 발생 불순물 band 의 증가와 더불어 가전자 대역과 전도대역 간의 중첩에 의하여 금속전도가 발생한다고 사료된다.

저온영역에서 발생한 전기전도가 variable range 
hopping에 의하여 지배 받고 있을 경우 열기전력의 온 도의존성은 $\alpha=\alpha_{0}+K(T)^{1 / 2}$ 로 표현할 수 있다. ${ }^{28,29)}$ Fig. 2 의 삽입그림에 나타난 것처럼 $x=0.3$ 의 열기전력의 온도 의존성은 저온영역에서 $T^{1 / 2}$ 에 직선적으로 fitting 되고 있 으나 고온영역에서는 벗어나고 있음을 알 수 있다. 직선 으로부터 얻어진 $K=-2.36 \mu \mathrm{V} / \mathrm{K}^{3 / 2}$ 였다.

Fig. 5 에는 $x=0.5$ 의 비저항의 온도의존성을 나타내었 다. Fig. 1(c)에 나타낸 것처럼, $x=0.5$ 조성의 경우 실험 온도범위에서 절연체적 거동을 나타내었다. 이전 $x=0.3$ 의 실험결과에서 알 수 있었듯이 저온영역에서의 전기전 도가 variable range hopping에 의하여 이루어 지고 있 음으로 $x=0.5$ 의 전기전도 역시 variable range hopping 으로 이루어질 가능성이 매우 높다고 사료된다. Fig. 5에 나타난 것처럼 저온 영역과 고온영역에서 명백한 온도의 존성의 변화를 나타내고 있음을 알 수 있다. 저온 과 고 온의 분기점이 되는 $T_{\mathrm{P}}$ 는 $3 d$ 천이금속 화합물의 Debye온 도 즉 $\theta_{\mathrm{D}}=h v_{\mathrm{ph}} / k_{\mathrm{B}}$ 의 $1 / 2$ 지점으로 생각 할 수 있다. ${ }^{17,18)}$ 저온영역 $\left(T<\theta_{\mathrm{D}}\right)$ 과 고온 영역 $\left(T>\theta_{\mathrm{D}}\right)$ 에서의 전기전도 가 variable range hopping기구에 의하여 이루어 진다면 비저항의 온도의존성은 $\mathrm{Eq}(1)$ 으로 나타 낼 수 있다. 저 온영역의 직선으로부터 얻어진 $\xi$ 와 $N\left(E_{\mathrm{F}}\right)$ 는 $0.059 \times 10^{6}$ $\mathrm{cm}^{-1}$ 그리고 $9.78 \times 10^{16} \mathrm{eV}^{-1} \mathrm{~cm}^{-3}$ 이었다 반면 고온영역에서 얻어진 $\xi$ 와 $N\left(E_{\mathrm{F}}\right)$ 는 $55.5 \times 10^{6} \mathrm{~cm}^{-1}$ 그리고 $6.62 \times 10^{21} \mathrm{eV}^{-1}$ $\mathrm{cm}^{-3}$ 이었다. 그러나 고온과 저온영역에서 얻어진 $\xi$ 와 $N\left(E_{\mathrm{F}}\right)$ 는 일반적으로 알려진 천이금속 산화물의 값보다 상 당히 크거나 혹은 작은 것이다. ${ }^{15-17)}$ 이러한 비저항의 온 도의존성으로 볼 때 $x=0.5$ 조성의 전기전도는 variable

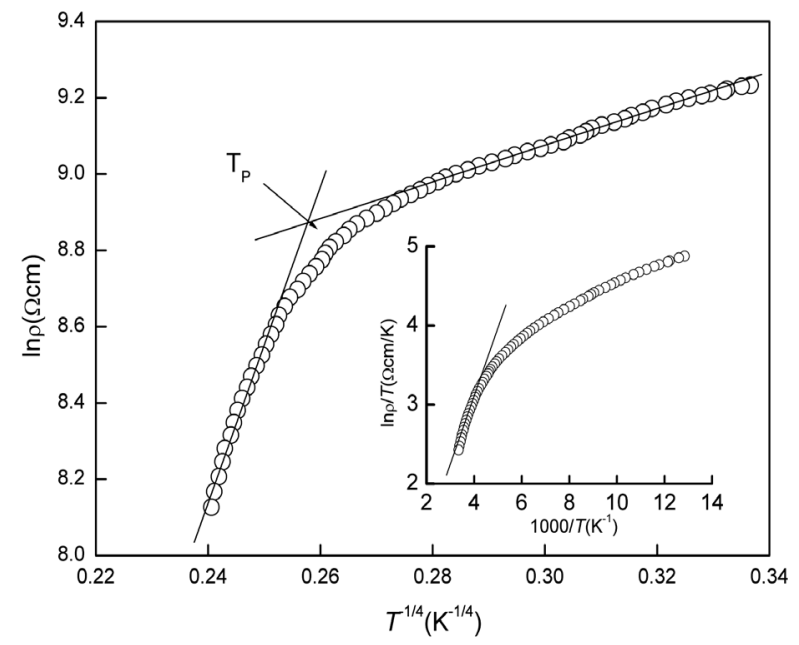

Fig. 5. Fit to low temperature resistivity measurements using the variable range hopping model. The solid lines are least squares fit to $T>T_{\mathrm{P}}$ and $T<T_{\mathrm{P}}$ data. [Inset]: Fit to high temperature resistivity measurements using the adiabatic small polaron model. The solid line represents the Arrhenius relation between the resistivity and temperature. range hopping기구로 매우 설명하기 어려울 것으로 사료 된다.

따라서 $\mathrm{LaNi}_{0.5} \mathrm{Ti}_{0.5} \mathrm{O}_{3}$ 의 전기전도는 다음과 같이 설명 할 수 있다. 모 물질인 $\mathrm{LaNiO}_{3}$ 의 전기전도주체 $\mathrm{Ni}^{3+}$ $\left(3 d^{7}, S=1 / 2\right)$ 의 $3 d_{x^{2}-y^{2}}$ 궤도는 반만 채워져 있는 반면, $\mathrm{LaNi}_{0.5} \mathrm{Ti}_{0.5} \mathrm{O}_{3}$ 의 $\mathrm{Ni}^{2+}\left(3 d^{8}\right)$ 는 low spin 상태로 존재하며 두개의 $e_{\mathrm{g}}$ 궤도는 병렬 $\operatorname{spin}(S=1)$ 과 더불어 한 개의 정 공에 의하여 채워져 있다. Furukawa등 ${ }^{30}$ 에 따르면 $\mathrm{Ni}^{3+}$ 와 $\mathrm{La}^{3+}$ 간에는 상호교환작용이 거의 존재하지 않기 때문 에 $\mathrm{Ni}^{3+}$ 의 증가는 재료의 공유결합을 약하게 하게 된다. 반면 산소 $\mathrm{O}^{2}-2 p_{\mathrm{z}}$ 궤도를 통한 $\mathrm{Ni}^{2+} 3 d_{\mathrm{z}}^{2}$ 궤도와 $\mathrm{La}^{3+} 6 s$ 궤도간의 강한 상호교환작용결과 강한 공유 결합이 발생 하게 된다. 따라서 $\mathrm{LaNi}_{0.5} \mathrm{Ti}_{0.5} \mathrm{O}_{3}$ 에는 $\mathrm{Ti}^{4+}$ 의 첨가량의 증 가에 따른 $\mathrm{Ni}^{2+}$ 의 증가로 인하여 강한 공유결합이 발생하 게 된다. $\mathrm{Ni}^{2+}$ 의 증가는 $\mathrm{Ni}^{2+}$ 와 $\mathrm{La}^{3+}$ 의 결합을 증가시키 며 비워진 $\mathrm{Ni} 3 d$ 궤도와 $\mathrm{O} 2 p$ 궤도간의 파동함수혼성을 약화시킴과 동시에 전도 band 폭을 감소시킨다. $x=0.5$ 의 경우 0.1 과 0.3 에 비하여 $\mathrm{Ni}^{3+}$ 의 양이 매우 적기 때 문에 전기전도는low spin 상태의 $\mathrm{Ni}^{2+}$ 에 존재하는 $\mathrm{e}_{\mathrm{g} \downarrow}$ 과 $\mathrm{e}_{\mathrm{g} \uparrow}$ level사이에 열적으로 활성화된 전도 carrier에 의하 여 발생하게 된다.

따라서 $x=0.5$ 의 전기전도는 가전자 대역 꼬리 위의 이 동도 모서리에 속박되어있는 전도 carrier의 단열 hopping 에 의하여 발생할 확률이 크다. ${ }^{31-34)}$ 즉 small polaron의 hopping이 $x=0.5$ 의 전도를 지배할 확률이 높다. 만약에 $x=0.5$ 의 전기전도가 small polaron의 hopping에 의하 여 발생한다면 전기저항률의 온도의존성은 $\rho / T \propto \rho_{0} \exp (-$ $\left.W_{H} / k_{B} T\right)$ 로 표현할 수 있다. ${ }^{31-34)}$ Fig. 5의 삽입그림에는 단열상태의 small polaron의 온도의존성을 나타내었다. 그 림에서 나타난 것처럼 고온영역에서 비저항의 온도의존 성은 직선적으로 fitting 되고 있으며 Arrhenius fitting으 로 얻어진 hopping 에너지 $W_{\mathrm{H}}$ 는 $0.08 \mathrm{eV}$ 였다.

\section{4. 결 론}

본 연구는 페로브스카이트 $\mathrm{LaNi}_{1-x} \mathrm{Ti}_{x} \mathrm{O}_{3}(x \leq 0.5)$ 세라믹 스의 열기전력 및 전기 비저항의 온도의존성을 $77 \mathrm{~K}-$ $300 \mathrm{~K}$ 범위에서 측정하였다. 측정된 $\mathrm{LaNi}_{1-x} \mathrm{Ti}_{x} \mathrm{O}_{3}(x \leq 0.5)$ 세라믹스의 열기전력의 온도의존성은 $A+B T$ 의 형으로 온 도에 직선적으로 증가 하고 있음을 알 수 있었다. 비저 항의 온도의존성은 $x=0.1$ 의 조성은 금속적 거동을 나타 내고 있었으며 $x=0.3$ 의 경우는 $150 \mathrm{~K}$ 부근에서 금속-절 연체 전이를 나타내었다. 반면 $x=0.5$ 의 경우 전체 온도 범위에서 절연체적 거동을 나타내었다. $x=0.1$ 조성의 비 저항의 온도의존성은 $\rho \propto T^{2}$ 으로 표현할 수 있었다. $x=$ 0.3 의 저온 영역 $(77 \mathrm{~K}$ 에서 $150 \mathrm{~K})$ 에서의 비저항의 온도 의존성은 $\ln \rho \propto T^{1 / 4}$ (variable range hopping)로 나타낼 
수 있었다. 또한 $x=0.5$ 의 경우 고온에서의 비저항의 온 도의존성은 $\rho / T \propto \rho_{0} \exp \left(-W_{H} / k_{B} T\right)$ 로 나타낼 수 있었다. 이 러한 실험 결과는 $x=0.1$ 조성의 전기전도는 spin polaron, $x=0.3$ 의 전기전도는 거의 속박화 된 $\mathrm{Ni}^{3+} 3 d$ polaron에 의한 variable range hopping 그리고 $x=0.5$ 의 경우는 small polaron hopping에 의하여 전도가 이루어지는 것 으로 사료된다.

\section{감사의 글}

본 연구는 2008년도 호원대학교 교내학술 연구비지원 으로 수행되었으며 이에 감사 드립니다.

\section{참 고 문 헌}

1. G. J. Snyder, C. H. Booth, F. Bridges, R. Hiskes, S. DiCarolis, M. R. Beasley and T. H. Geballe, Phys. Rev. B., 55, 6453 (1998).

2. J. W. Park, M. S. Kim, J. G. Park, I. P. Swainson, H. C. Ri, H. J. Lee, K. H. Kim, T. W. Noh, S. W. Cheong and C. H. Lee, J. Kor. Phys. Soc,, 36, 412 (2000).

3. J. G. Park, M. S. Kim, H. C. Ri, K. H. Kim, T. W. Noh, and S. W. Cheong, Phys. Rev. B., 60, 14804 (1999).

4. W. H. Jung, J. H. Sohn, J. H. Lee. J. H. Sohn, M. S. Park, and S. H. Cho, J. Am. Ceram. Soc., 83, 797 (2000).

5. Y. D. Li, J. H. Zhang, C. S. Xiong and H. W. Liao, J. Am. Ceram. Soc., 83, 980 (2000).

6. A. I. Mills, Phys. Rev. B., 53, 8434 (1996).

7. A. I. Mills, Phys. Rev. B., 55, 6405 (1997).

8. K. P. Rajeev, G. V. Shivashankar and A. K. Raychaudhuri, Solid State Comm., 79, 591 (1991).

9. K. M. Satyalakshmi, R. M. Mally, K. V. Ramanathan, X. D. Wu, K. Brainard, D. C. Gautier, N. Y. Vasanthachary and M. S. Hegde, Appl. Phys. Lett., 62, 1223 (1993).

10. J. B. Torrance, P. Lacorre, A. I. Nazzal, E. J. Ansaldo and C. H. Nidermayer, Phys. Rev. B., 45, 8209 (1992).

11. J. Zaanen, G. A. Sawatzky and J. W. Allen, Phys. Rev. Lett., 55, 418 (1985).

12. M. Medarde, A. Fontaine, J. L. Garcia, J. Rodriguez, M, de Santis, M. Sacchi, G. Rossi and P. Lacorre, Phys. Rev. B., 46, 14975 (1992).
13. S. R. Barman, A. Chainani and D. Sarma, Phys. Rev. B., 49, 8475 (1994).

14. J. K. Vassiliou, M. Hornsbostel, R. Ziebarth and F. J. Disalvo, J. Solid. State Chem., 81, 208 (1989).

15. J. Blasco, M. Castro and J. Garcia, J. Phys.: Condens. Matter., 6, 5875 (1994).

16. P. C. Canfield, J. D. Thompson, S. W. Cheong and L. W. Rupp, Phys. Rev. B., 47, 12357 (1993).

17. N. Gayathri, A. K. Raychaudhuri, X. Q. Xu, J. L. Peng and R. L. Greene, J. Phys.: Condens. Matter., 10, 1323 (1998)

18. K. P. Rajeev, G. V. Shivashankar and A. K. Raychaudhur, Solid. State Comm., 79, 1112 (1991).

19. W. H. Jung, H. Nakatsugawa and R. Iguchi, J. Solid State. Chem., 166, 466 (1997).

20. E. Iguch and W. H. Jung, J. Phys. Soc. Jap., 63, 3078 (1994).

21. V. Kulkarrni, K. R. Priolkar, P. R. Sarode, R, Rawat, A. Banerjee and S. Emura, J. Phys.: Condens. Matter., 20, 75203 (2008)

22. K. Sreedhar, J. M. Honig, M. Darwin, M. McElfresh, P. M. Shand, J. Xu, B. C. Crooker and J. K. Spalek, Phys. Rev. B., 46, 6328 (1992).

23. S. Wang, K. Li, Z. Chen and Y. Zhang, Phys. Rev. B., 61, 575 (2000).

24. T. T. M. Palsta., A. P. Ramirez, S. W. Cheong, B. R. Zegarski, P. Schiffer and J. Zaanen, Phys. Rev. B., 56, 5140 (1997).

25. V. H. Crespi, L. Lu,. Y. X. Jia, K. Khazeni, A. Zettle and M. L. Cohen, Phys. Rev. B., 53, 14303 (1996).

26. N. F. Mott, Adv. Phys., 39, 55 (1990).

27. N. F. Mott, J. Phys.: Condens. Matter., 5, 3487 (1993).

28. G. H. Zheng, Y. Q ma, X. B. Zhu and Y. P. Sun, Solid State Comm., 142, 217 (2007)

29. B. C. Zhao, Y. P. Sun, W. J. Lu, J. Yang, X. B. Zhu and W. H. Song, Solid State Comm., 139, 209 (2006).

30. Y. Furukawa and S. Wada, J. Phys. Soc. Jap., 61, 1182 (1992).

31. W. H. Jung, J. Phys.: Condens. Matter., 10, 8553 (1998).

32. W. J. Weber, C. W. Griffin and J. L. Bates, J. Am. Ceram. Soc., 70, 265 (1987).

33. P. Brahma, S. Banerjee, S. Chakraborty and D. Chakravorty, J. Appl Phys., 88, 6526 (2000).

34. S. Wang, K. Li, Z. Chen and Y. Zhang, Phys. Rev. B., 61, 575 (2000). 